\title{
Plasma Glutathione S-Transferase in Carbon Tetrachrolide Treated Rats and Its Association to Hepatic Cytosolic Isozymes
}

\author{
Takashi IGARASHI, Hideko MURAMATSU, Shigeru OHMORI, \\ Koichi UENO, Haruo KITAGAWA and Tetsuo SATOH*
}

\author{
Department of Biochemical Pharmacology and Biotoxicology. Faculty of Pharmaceutical Sciences, \\ Chiba University, Chiba 260, Japan \\ *Department of Pharmacology and Toxicology. Tokyo College of Pharmacy, \\ Hachioji. Tokyo 192-03. Japan \\ Accepted November 21. 1987
}

\begin{abstract}
The effect of carbon tetrachloride $\left(\mathrm{CCl}_{4}\right)$ treatment on plasma and liver cytosolic glutathione S-transferase (GST) activities was investigated in rats. $\mathrm{CCl}_{4}$ was intraperitoneally administered at a dose of $0.5 \mathrm{ml} / \mathrm{kg}$. The elevation of plasma GST activity paralleled the increase of plasma glutamate pyruvate transaminase activity after the administration of $\mathrm{CCl}_{4}$. Liver cytosolic GST activities were significantly decreased by $\mathrm{CCl}_{4}$ treatment. To establish the relationship of plasma GST with liver cytosolic isozymes. Western blot analysis using antibodies against cytosolic GST $1-2$ and 3-4 was performed. The Western blots showed the existence of GST $1-2$ and 3-4 in plasma at $24 \mathrm{hr}$ after $\mathrm{CCl}_{4}$ treatment. The data thus strongly suggest that cytosolic GSTs are lost from the liver to plasma as a consequence of liver damage. The Western blot analysis of plasma GST may be useful for monitoring liver damage.
\end{abstract}

The glutathione S-transferases (GST: EC 2.5.1.18) are a family of multifunctional proteins involved in xenobiotics metabolism (1). These enzymes are the most abundant in the liver, comprising 5 to $10 \%$ of the soluble hepatic proteins (2). The treatment of rats with carbon tetrachloride $\left(\mathrm{CCl}_{4}\right)$, a well known hepatotoxic chemical, has been shown to cause the decrease of hepatic cytosolic GST activity (3). $\mathrm{CCl}_{4}$ induced hepatotoxicity would be also accompanied by an elevation of serum GST activity as well as an increase in serum glutamate-pyruvate transaminase activity (3).

Multiple forms of GST have recently been

Abbreviations: GST, glutathione S-transferase: GPT. glutamate pyruvate transaminase: $\mathrm{CCl}_{4}$, carbon tetrachloride; CDNB, 1-chloro-2,4-dinitrobenzene; DCNB, 1,2-dichloro-4-nitrobenzene; t-PBO, transphenylbuten-3-one: BSA, bovine serum albumin; PBS, $20 \mathrm{mM}$ potassium phosphate, $0.15 \mathrm{M} \mathrm{NaCl}$, pH 7.4: SDS-PAGE, sodium dodecyl sulfatepolyacrylamide gel electrophoresis. identified in various organs such as the liver, and so more definitive information on the source of the serum GST activity will be necessary; however, this still remains to be clarified. In the present study, we examined the alteration of hepatic cytosolic and plasma GST activity in $\mathrm{CCl}_{4}$-poisoned rats and also describe the relationship of plasma GST(s) with hepatic cytosolic GST isozymes by immunoblotting.

\section{Materials and Methods}

Animal treatment: Seven week-old male Sprague Dawley rats were used. $\mathrm{CCl}_{4}$ diluted with corn oil was administered to the rats $(0.5 \mathrm{ml} / \mathrm{kg}$, i.p.). Control animals received an equivalent volume of corn oil alone. All rats were fasted for $24 \mathrm{hr}$ before $\mathrm{CCl}_{4}$ administration. Blood was collected under ether anesthesia from the abdominal aorta and centrifuged at 3,000 rom for $10 \mathrm{~min}$ at $4^{\circ} \mathrm{C}$, and then the plasma was separated. The livers were quickly removed and $20 \%$ (W/V) homogenates were prepared. The homo- 
genate was centrifuged at $105,000 \times \mathrm{g}$ for 60 min. The resulting clear supernatant after the removal of the lipid layer at the top of the centrifuge tubes was used as the cytosol for all assays.

Assays: Glutamate-pyruvate-transaminase (GPT) present in the plasma was determined using commercial assay kits of latron K.K. (Tokyo, Japan). GST activity was measured by the method of Habig et al. Protein was determined by the procedure of Lowry et al. (5) with bovine serum albumin as a standard.

Chemicals: 1-Chloro-2,4-dinitrobenzene (CDNB), 1,2-dichloro-4-nitrobenzene (DCNB), trans-phenylbuten-3-one (t-PBO) and $\mathrm{CCl}_{4}$ were purchased from Wako Pure Chemical Industries, Ltd. (Tokyo, Japan). All other reagents used were of analytical grade.

Purification of GST and antibody production: The hepatic cytosol from male rats was dialyzed against $10 \mathrm{mM}$ Tris- $\mathrm{HCl}(\mathrm{pH} 8.0)$. The dialysate was applied onto an S-hexylglutathione-affinity column. which was prepared from epoxy-activated Sepharose 6B (Pharmacia Fine Chemicals) according to the method of Mannervik and Guthenberg (6). GST is eluted with $10 \mathrm{mM}$ Tris- $\mathrm{HCl}-0.2 \mathrm{M}$ $\mathrm{NaCl}(\mathrm{pH} \mathrm{8.0)}$ containing $5 \mathrm{mM} \mathrm{S}$-hexylglutathione. The eluates were pooled and concentrated to a small volume by ultrafiltration with a Diaflo PM-10 membrane, and then charged onto a column of Sephadex G-25 to remove S-hexylglutathione. The thus purified GSTs showed three distinct bands of GST subunits, $Y_{a}(1), Y_{b} 1(3) / Y b 2(4)$ and $Y_{C}(2)$, on SDS-polyacrylamide gel electrophoresis. in which Yb1 (3) and Yb2 (4) subunits migrated to the same position.

The purification of GST $1-2$ and 3-4 isozymes and their antibody production were carried out as described previously (7).

Immunotitration of plasma GST activity: The activity inhibition test with anti GST 1-2 and 3-4 antibodies was performed as follows: Twenty to $300 \mu$ portions of the antisera were added to $0.05 \mathrm{ml}$ of $\mathrm{CCl}_{4}$ treated rat plasma (GST activity to CDNB, $2.41 \mathrm{U} /$ $\mathrm{ml}$ ), and the final volume was brought up to $0.35 \mathrm{ml}$ with $10 \mathrm{mM}$ sodium phosphate-0.9\% $\mathrm{NaCl}(\mathrm{pH}$ 7.4). The mixtures were left overnight at $4^{\circ} \mathrm{C}$ and then centrifuged at $10,000 \times g$ for $5 \mathrm{~min}$. The resulting supernatant was used for assaying GST activity towards CDNB. The degree of inhibition of the activity by each antibody was expressed as a percentage of the control activity using nonimmune control serum.

Western blot analysis: Western blots were performed as described by Towbin et al. (8) with slight modifications. After electrophoresis in a slab containing $12.5 \%$ SDSpolyacrylamide as described by Laemmli (9), the proteins separated on the gel were transfered electrophoretically at $1 \mathrm{~mA} / \mathrm{cm}^{2}$ gel for $3 \mathrm{hr}$ to a nitrocellulose sheet in a buffer solution composed of $0.1 \mathrm{M}$ Tris-base/0.192 M glycine $/ 20 \%$ methanol. The nitrocellulose sheet was blocked with $3 \%$ BSA/PBS for $15 \mathrm{~min}$ at $40^{\circ} \mathrm{C}$ and then washed 6 times in $30 \mathrm{~min}$ with PBS and incubated with $1 / 200$ diluted anti GST $1-2$ or 3-4 antiserum in PBS for one hr at room temperature. The sheet was then washed 6 times in 30 min with PBS and incubated with $1 / 100$ diluted goat antirabbit lgG (heavy and light chains specific) in PBS for $15 \mathrm{~min}$ at room temperature. After further washing, the sheet was incubated with $1 / 2000$ diluted horseradish peroxidase anti-peroxidase (PAP) complex in PBS for $15 \mathrm{~min}$ at room temperature. The sheet was then washed 6 times in 30 min with PBS and stained with $20 \mathrm{mg}$ of 3, 3'-diaminobenzidine $/ 20 \mu$ of $30 \% \quad \mathrm{H}_{2} \mathrm{O}_{2}$ in $80 \mathrm{ml}$ of $50 \mathrm{mM}$ Tris- $\mathrm{HCl}$ (pH 7.6).

\section{Results}

The time course of plasma GPT and GST activities after $\mathrm{CCl}_{4}$ treatment is illustrated in Fig. 1. The responses of plasma GPT and GST were similar, both reaching a maximum $24 \mathrm{hr}$ after the dose and thereafter declining. The rise in plasma GST activities was approximately 19 -fold of the control at $24 \mathrm{hr}$ later. The alteration of hepatic cytosolic GST activities by the administration of this hepatotoxin is shown in Fig. 2. The transferase activities towards CDNB, DCNB and t-PBO as substrates were all decreased in a timedependent manner by the treatment. These changes in plasma and cytosolic GST activities during the treatment were examined by SDS-PAGE analysis and immunoblotting.

Western blot analyses using antibodies 


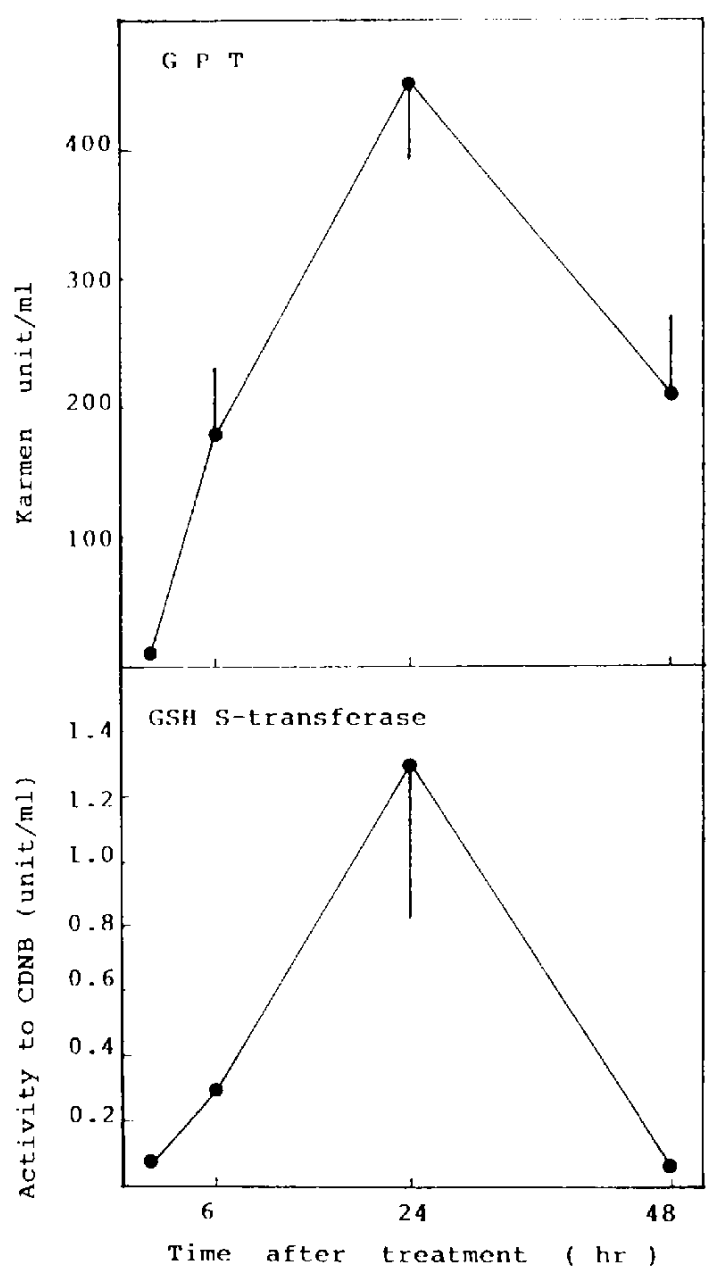

Fig. 1. Effect of carbon tetrachlaride treatment on plasma GPT and plasma GST activity in rats. Plasma GST activity was measured with CDNB as a substrate. The values represent the mean \pm S.E. from four to five rats.

against GST $1-2$ and 3-4 were carried out to determine which isozymes were decreased in the cytosol and expressed in the plasma during $\mathrm{CCl}_{4}$ treatment (Fig. 3). Results showed that ant GST 1-2 antiserum did not cross-react with the Yb1 (3) and Yb2 (4) subunits, and that anti GST 3-4 antiserum did not react with the $Y_{C}(2)$ subunit, while it reacted with the Ya (1) subunit. The subunits of cytosolic GSTs were apparently diminished by $\mathrm{CCl}_{4}$ treatment, as shown from the pattern of protein staining. The Western blots demonstrated that $\mathrm{CCl}_{4}$ treatment re- sulted in the quantitative decrease of isozymes of the 1-2 and 3-4 type present in the liver cytosol. With respect to plasma GST, the pattern of protein staining of the subunits was not clear and little different between the control and the $\mathrm{CCl}_{4}$-treated rats. The analysis by Western blotting, however. has revealed that $\mathrm{CCl}_{4}$-treated rat plasma strongly reacted with antibodies against cytosolic GST $1-2$ and 3-4, but control plasma did not.

As shown in Fig. 4, the GST activity of $\mathrm{CCl}_{4}{ }^{-}$ treated rat plasma was inhibited by immunotitration with anti GST $1-2$ and 3-4 antiserum. It was also found that plasma GST activity after $\mathrm{CCl}_{4}$ treatment was precipitated to a much greater extent by anti GST 3-4 than 1-2 antiserum.

\section{Discussion}

Bass et al. (10) demonstrated that the plasma level of ligandin, one of the GST isozymes, rose greatly in $\mathrm{CCl}_{4}$-treated rats by using the radioimmunoassay for ligandin, suggesting that plasma ligandin is a sensitive index of experimental hepatocellular necrosis. Later, ligandin has been identified as a dimer composed of the $\mathrm{Ya}$ (1) subunit and identical with GST 1-1 (11). Beckett and Hayes (12) have also used the radioimmunoassay for estimating plasma GST level and demonstrated that the increase of plasma concentrations of GST YaYa (also named GST 1-1) occurred by the administration of hepatotoxic drugs including paracetamol, halothane, triiodothyronine and so on. Recently. it has been shown that hepatic cytosolic major GSTs are composed of various pairs of four distinct subunits: $Y_{a}(1), Y_{c}(2), Y b 1$ (3) and $Y b 2$ (4), on the basis of immunological properties and substrate specificities $(13,14)$. Mannervik and Jensson (13) indicated that the six major transferases (GST 1-1, 1-2, 2-2, 3-3, 3-4 and $4-4$ ) in rat hepatic cytosol can be classified into two groups, $1-2$ and 3-4. CDNB is generally a good substrate for all isozymes of GSTs, but DCNB and t-PBO are active for only isozymes having subunit 3 and 4 , respectively (15). The decrease of cytosolic GST activities towards DCNB and t-PBO as well as CDNB suggests that not only GST $1-2$ but $3-4$ isozymes may be altered by $\mathrm{CCl}_{4}$ treatment. These alteration in GST isozymic 


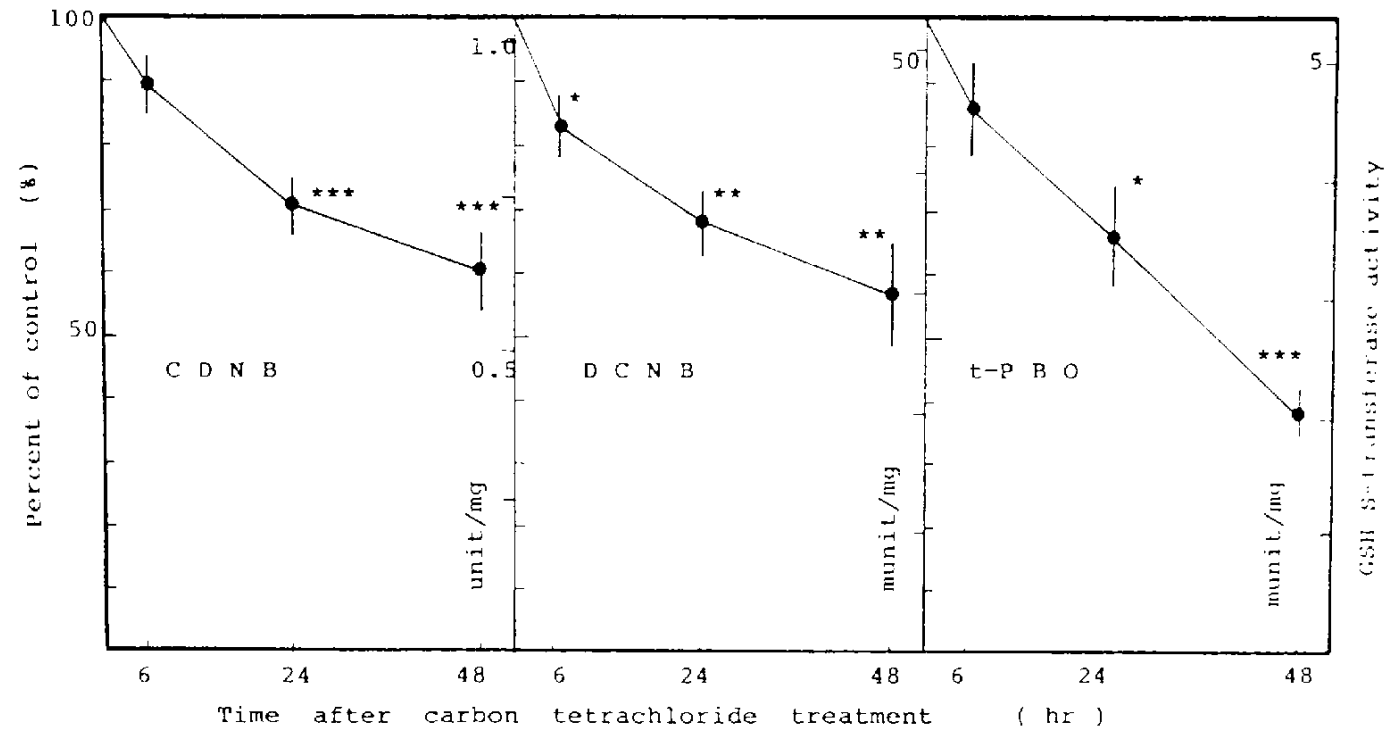

Fig. 2. Effect of carbon tetrachloride treatment on hepatic cytosolic GST activities. The values represent the mean \pm S.E. from four to five rats. ${ }^{*} P<0.05,{ }^{* * P} P<0.01,{ }^{* * *} P<0.001$ vs. control.
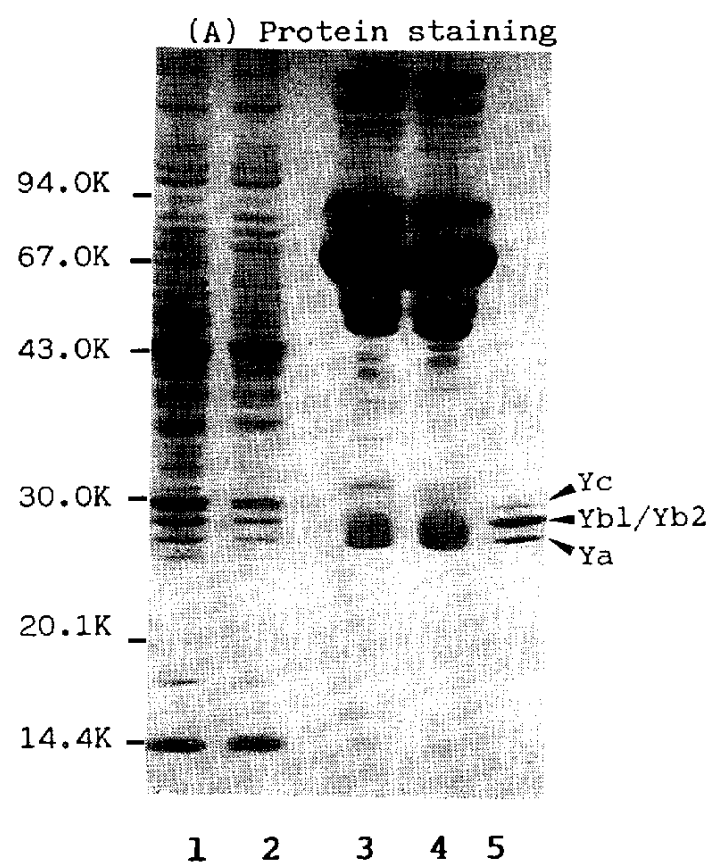

Western blot
(PAP staining)

(B) anti GST $1-2$

(C) anti GST $3-4$

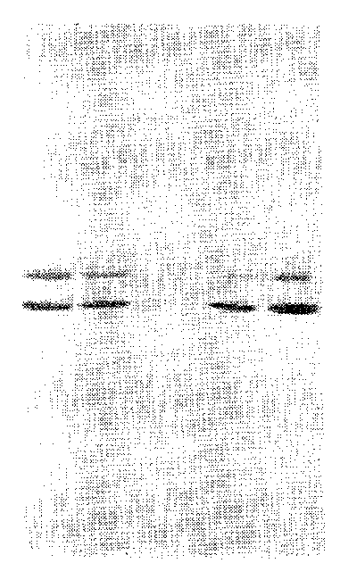

$\begin{array}{lllll}1 & 2 & 3 & 4 & 5\end{array}$

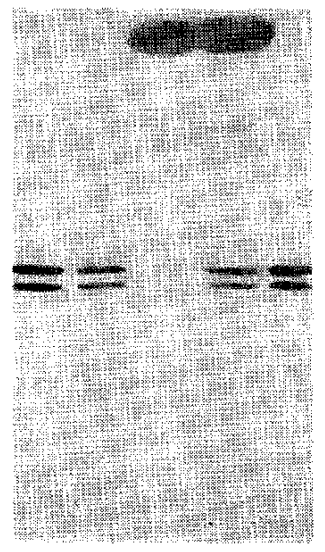

$\begin{array}{lllll}1 & 2 & 3 & 4 & 5\end{array}$

Fig. 3. SDS-PAGE and Western blot analysis of cytosolic and plasma GST after the treatment of rats with $\mathrm{CCl}_{4}$ for $24 \mathrm{hr}$. Each sample of cytosol and plasma diluted was completely dissociated in boiling water for 2 min with solubilization buffer containing $1 \%$ SDS, $0.0675 \mathrm{M} \mathrm{Tris-} \mathrm{HCl}(\mathrm{pH} 6.8), 10 \%$ glycerol, $5 \%$ 2 -mercaptoethanol and $0.001 \%$ bromophenol blue as the dye for protein staining (A), and with that of $1.35 \%$ SDS. $0.09 \mathrm{M}$ Tris- $\mathrm{HCl}(\mathrm{pH} 6.8), 13.5 \%$ glycerol, $6.76 \% 2$-mercaptoethanol and $0.001 \% \mathrm{pyronin} Y$ as the dye for Western blotting ( $B$ and $C$ ). After SDS-PAGE, one of the gels was blotted onto nitrocellulose sheets as described in Materials and Methods. The other gel was stained with Coomassie Brilliant Blue $\mathrm{R}-250.1$ and 2: control and $\mathrm{CCl}_{4}$ treated cytosol, respectively (applied proteins per lane: $15 \mu \mathrm{g}(\mathrm{A}) .2 \mu \mathrm{g}$ ( $\mathrm{B}$ and $\mathrm{C}$ ). 3 and $4:$ coritrol and $\mathrm{CCl}_{4}$ treated plasma, respectively (20 $\mu$ of each plasma diluted 32 -fold ( $A$ ) and 50 -fold ( $B$ and $C$ ) was applied per lane). 5: male transferases obtained from the

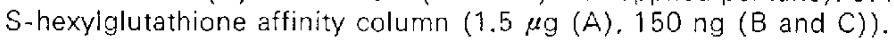




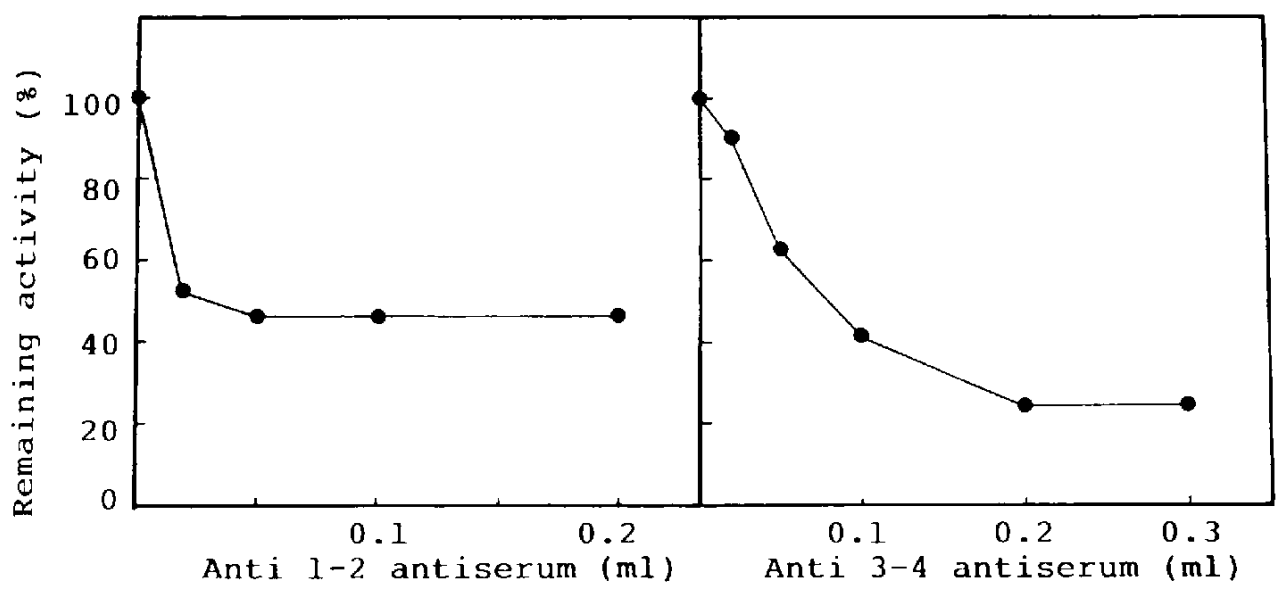

Fig. 4. Immunotitration of plasma GST activity after $\mathrm{CCl}_{4}$ treatment by anti GST $1-2$ and 3-4 antibodies.

composition was ascertained by Western blot analysis, as illustrated in Fig. 3.

With respect to plasma GST, there has been little information about the other GSTs, except for GST 1-1. To investigate the plasma GST activity increased by $\mathrm{CCl}_{4}$ treatment, we have employed immunochemical analyses using Western blots. The protein staining pattern of plasma GST subunits failed to detect the difference between the control and $\mathrm{CCl}_{4}$ treated rats. The present study shows, however, that the Western blot analysis for GSTs can be applied to the detection of GST isozymes in the blood stream. It has provided direct evidence for the existence of not only GST $1-2$ but also GST $3-4$ isozymes in the plasma of $\mathrm{CCl}_{4}$-treated rats. This indicates strongly that hepatic GST $1-2$ and 3-4 isozymes were both released into the plasma after administration of $\mathrm{CCl}_{4}$. The Western blot analysis described this paper seems to be simple, reproducible and a faster procedure than radioimmunoassay and thus may be an alternative useful method for monitoring hepatotoxicity.

Acknowledgments: The authors wish to thank Miss Emiko Ishibashi for her excellent technical assistance. This work was supported in part by a Grar,t-in-Aid for Encouragement of Young Scientist from the Ministry of Education, Scinece and Culture of Japan and by a grant from Uehara Memorial Foundation, Japan.

\section{References}

1 Boyland, E. and Chasseaud, L.F.: Role of glutathione and glutathione S-transferase in mercapturic acid biosynthesis. Adv. Enzymol. 32, $173-219(1969)$

2 Jakoby, W.B.: The glutathione S-transferases: a group of multifunctional detoxification proteins. Adv. Enzymol. 46, 383-414 (1978)

3 Aniya, Y. and Anders, M.W.: Alteration of hepatic glutathione $S$-transferases and release into serum after treatment with bromobenzene. carbon tetrachloride, or $\mathrm{N}$-nitrasodimethylamine. Biochem. Pharmacol. 34, 4239-4244 (1985)

4 Habig, W.H., Pabst, M.J. and Jakoby, W.B.: Glutathione S-transferases: the first enzymatic step in mercapturic acid formation. J. Biol. Chem. 249, 7130-7139 (1974)

5 Lowry, O.H., Rosebrough, N.J., Farr, A.L. and Randall, R.L.: Protein measurement with Folin phenol reagent. J. Biol. Chem. 193, 265-275 (1951)

6 Mannervik, B. and Guthenberg, C.: Glutathione transferase (Human placenta). Methods Enzymol. 77, 231-235 (1981)

7 Igarashi, T., Satoh, T., Iwashita, K., Ono, S., Ueno, K. and Kitagawa, H.: Sex difference in subunit composition of hepatic glutathione Stransferase in rats. J. Biochem. 98, 117-123 (1985)

8 Towbin, H., Staehlin, T. and Gordon, J.: Electrophoretic transfer of proteins from polyacrylamide gels to nitrocellulose sheets: procedure and some applications. Proc. Natl. Acad. Sci. U.S.A. 76, 4350-4354 (1979)

9 Laemmli, U.K.: Cleavage of structual proteins during the assembly of the head of bacteriophage T4. Nature 227, 680-685 (1979)

10 Bass, N.M., Kirsch, R.E., Tuff, S.A. and Saunders, S.J.: Radioimmunoassay of plasma ligandin: a 
sensitive index of experimental hepatocellular necrosis. Gastroenterology 75, 589-594 (1978)

11 Hayes, J.D., Strange, R.C. and Percy-Robb, I.W.: A study of the structures of the YaYa and YaYc glutathione $S$-transferases from rat liver cytosol. Biochem. J. 197, 491-502 (1981)

12 Beckett, G.J. and Hayes, J.D.: Plasma glutathione S-transferase measurements and liver disease in man. J. Clin. Biochem. Nutr. 2, 1-24 (1987)

13 Mannervik, B. and Jensson, $H_{\text {.: }}$ Binary combinations of four protein subunits with different catalytic specificities explain the relationship between six basic glutathione S-transferases in rat liver cytosol. J. Biol. Chem. 257, 9909-9912 (1982)

14 Tu, C-P,D., Weis, M.J, and Reddy, C.C.: Subunit composition of rat liver glutathione $S$ transferases. Biochem. Biophys. Res. Commun. 108, 461-467 (1982)

15 Mannervik, B.: The isoenzymes of glutathione transferase. Adv. Enzymol. Relat. Areas Mol. Biol. 57, 357-417 (1985) 